BMJ

Open

Gastroenterology

\section{Accelerated gastric emptying is associated with improved aspiration efficiency in obesity}

\author{
Eric J Vargas, ${ }^{\circledR}$ Andrew C Storm, Fateh Bazerbachi, Barham K Abu Dayyeh
}

To cite: Vargas EJ, Storm AC, Bazerbachi F, et al. Accelerated gastric emptying is associated with improved aspiration efficiency in obesity. BMJ Open Gastro 2019;6:e000273. doi:10.1136/ bmjgast-2019-000273

Received 10 January 2019 Revised 4 February 2019 Accepted 11 February 2019
Check for updates

C Author(s) (or their employer(s)) 2019. Re-use permitted under CC BY-NC. No commercial re-use. See rights and permissions. Published by BMJ.

Division of Gastroenterology and Hepatology, Mayo Clinic Minnesota, Rochester Minnesota, USA

Correspondence to Dr Barham K Abu Dayyeh; AbuDayyeh.Barham@mayo.edu

\begin{abstract}
Background The overall effectiveness of aspiration therapy (AT) for obesity relies on optimal aspiration timing after a meal, which can vary depending on a patient's rate of gastric emptying (GE). Our aim was to identify if baseline GE rates were associated with differences in aspiration efficiency (AE).

Methods Subjects from an ongoing AT clinical trial were enrolled in this study. AE was calculated as the absolute gastric residual and calories aspirated at 20 and 40 min. Participants were then divided by baseline GE rate into two groups (slow vs fast). Wilcoxon rank-sum test was used to compare $A E$ at 20 and 40 min between the groups. Exploratory linear regression was used to assess relationship between $\mathrm{GE}$ and $\mathrm{AE}$.

Results 7 patients ( $85 \%$ female) were coenrolled in the study. Mean age and body mass index were $39.8 \pm 9.44$ and $43 \pm 5$, respectively. AE did not significantly differ between the 20 and 40 min time points for the group as a whole $(34.3 \%$ vs $36.9 \%$; $p>0.5)$. However, those with fast GE aspirated more calories than those with slow GE (20 min: $200 \mathrm{kcal}$ vs $72.5 \mathrm{kcal} ; 40 \mathrm{~min}: 154 \mathrm{kcal}$ vs $63 \mathrm{kcal})$ $(p=0.05)$. On linear regression, delayed GE was associated with poorer aspiration (20 min: $\beta=-107$ calories;

$\left.p=0.019 ; R^{2}=0.7\right) .4 / 7$ patients had significant differences in residual/caloric aspiration across the two time points. Conclusion Patients undergoing AT may benefit from a GE test to optimise their AE. Paradoxically faster GE times saw better aspiration. Prospective studies are revealing a personalised approach to obesity.
\end{abstract}

\section{INTRODUCTION}

Aspiration therapy (AT) with the AspireAssist System is a Food and Drug Administration-approved endoscopic treatment option for adults with body mass index (BMI) 35-55 who have failed prior non-surgical weight loss attempts. The device is endoscopically placed and removed similarly to percutaneous endoscopic gastrostomy (PEG) tubes, and can remain in place for several years. The AspireAssist device (King of Prussia, PA, USA) is composed of a modified PEG tube (A-tube), a skin port and an accessory device that allows patients to dispose up to $30 \%$ of their meal leading to
Summary box

What is already known about this subject?

- Despite the effectiveness of aspiration therapy producing a mean $15 \%$ total body weight loss at 1 year a significant proportion of patients fail to achieve more weight loss compared with placebo.

What are the new findings?

- Subjects with accelerated gastric emptying at baseline aspirated more calories at any time point compared with those with normal or slower emptying. Thus, delayed gastric emptying at baseline was associated with poorer aspiration efficiency.

How might it impact on clinical practice in the foreseeable future?

- Patients with baseline gastric emptying rate $\left(\mathrm{T}_{1 / 2}\right)$ greater than 94 min should consider other treatment options for obesity. In patients undergoing aspiration therapy, poor response can be assessed using gastric scintigraphy to optimise aspiration time points.

weight loss. Results from the US multicentre Pivotal Aspiration Therapy with Adjusted Lifestyle 'PATHWAY' randomised clinical trial demonstrated a mean $14.2 \% \pm 9.8 \%$ total body weight loss (\% TBWL) among completers at 1 year with improvements in metabolic parameters and quality of life. ${ }^{1}$ A following multicentre postapproval study validated their findings, revealing even greater 1 year $\%$ TBWL at $18.2 \%+9.4 \%$, with maintained weight loss at 4 years. ${ }^{2}$ However, in the PATHWAY study, the investigators found that early responders who lost greater than 5\% TBWL by 14 weeks lost significantly more weight at 1 year than those who failed to reach $5 \%$ TBWL $(17.2 \% \pm 8.7 \%$ vs $4.9 \% \pm 6.3 \%)$. This observed variability in weight loss is not unique to the PATHWAY study but rather ubiquitous in weight loss trials with medications, endoscopic devices and even bariatric surgery, highlighting the complexities behind energy homeostasis in obesity. 
The stomach's role in appetite regulation has now expanded with faster gastric emptying (GE) and larger accommodating volume being associated with obesity. These interindividual differences in baseline GE and volumes have implications when it comes to specific treatments, with proof-of-concept studies revealing associations between changes in GE and weight loss response. $^{3-7}$ The role of baseline GE on AT has yet to be investigated.

In the pilot study, Sullivan $e a^{8}{ }^{8}$ used bomb calorimetry in seven subjects to determine the optimal timing for aspiration. They reported optimal aspiration efficacy occurs when aspirating at 20 min compared with 60 min after a $450 \mathrm{kcal}$ meal. However, this optimal aspiration timing in patients may depend on multiple factors such as differences in GE rates, gastric volumes and distribution of food in the stomach, for example. These factors cannot be evaluated using traditional bomb calorimetry, and are evaluated better using traditional gastric scintigraphy.

Thus, our study had several objectives: first, describe the GE rates between individuals undergoing AT; second, determine if the optimal aspiration timing varies between patients; and third, identify the association between GE rates and optimal aspiration timing.

\section{METHODS}

\section{Study subjects}

Patients from a single centre who were already enrolled in a multicentre study evaluating the efficacy and safety of the AspireAssist were prospectively coenrolled in this study.

\section{Data collection and methodology}

Patients' demographics such as age, gender, and BMI at the start of the substudy were prospectively collected. For the study, three standard solid GE studies were performed on three different days, 1 week apart, for every subject. A standard radiolabelled scrambled egg and toast, and skim milk beverage ( $315 \mathrm{kcal})$ were given at every visit. The first visit evaluated the food bolus at $0,10,20,30,40,60,90$, and 120 min after consumption of the radiolabelled meal to establish a baseline gastric residual at these times in addition to the baseline $T_{1 / 2}$ measured in minutes. The second and third visits were performed with aspiration at 20 or 40 min with preaspiration and postaspiration residuals calculated to estimate the amount of residual aspirated. Subjects' medication lists were reviewed prior to GE test to ensure none were performed while on antimotility or promotility agents.

\section{Outcome of interest}

Aspiration efficacy

Aspiration efficiencies (AE) at 20 and $40 \mathrm{~min}$ were respectively calculated by subtracting the postaspiration gastric residual from the preaspiration residual to capture the amount aspirated. The amount of calories aspirated was then estimated by multiplying the per cent residual by the caloric content of the meal (315 kcal). The study subjects served as their own controls for the 20 vs 40 min comparison. AE stratified by baseline GE rate $\left(\mathrm{T}_{1 / 2}\right)$ was also performed for each time point.

\section{Statistical analyses}

Demographical data were analysed using parametric and non-parametric methods based on their distribution. Basic box plots were used to graphically describe the gastric residuals and baseline $\mathrm{T}_{1 / 2}$. For our first outcome of interest, the Wilcoxon signed-rank test was used to compare median AEs at 20 and 40 min between the paired data. Wilcoxon rank-sum test was then used to compare $\mathrm{AE}$ at 20 and $40 \mathrm{~min}$ by their baseline $\mathrm{GE}$ group (slow vs normal). Exploratory linear regression was used to assess the relationship between baseline GE with aspiration efficacy at each time point. All tests were two sided with statistical significance set at an alpha $=0.05$. Analyses were performed with JMP Pro V.13 statistical software by SAS (Cary, NC).

\section{RESULTS}

Seven patients from the ongoing clinical trial were prospectively enrolled in this substudy. Mean age of subjects was $39.8 \pm 9.44,85 \%$ were female and mean BMI was $43 \pm 5$. Median GE was 94.3 min (range 81.2 $175)$. Gastric residuals at $40 \mathrm{~min}$ for solid foods varied anywhere from $60 \%$ to $85 \%$, whereas at $20 \mathrm{~min}$ it varied from $70 \%$ to $85 \%$. In liquids, 40 min residuals ranged from $20 \%$ to $37 \%$ and 20 min residuals ranged from $30 \%$ to $53 \%$ (figure 1). There were no differences between the solid gastric residuals from their baseline study and their preaspiration gastric residual.

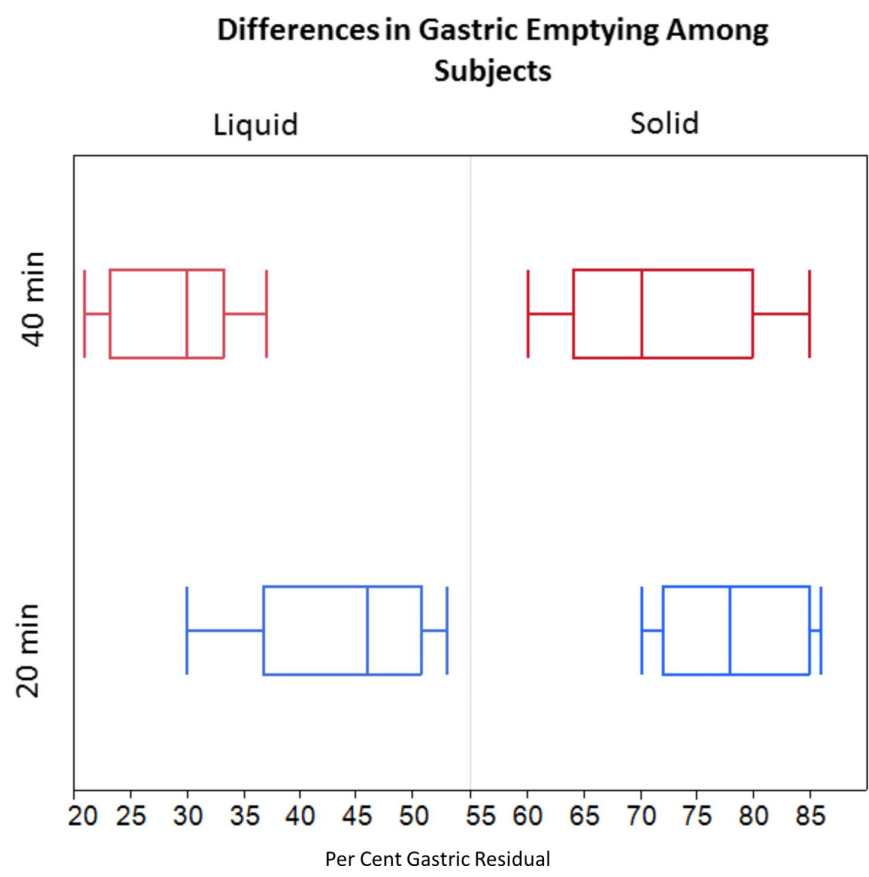

Figure 1 Variability in gastric residuals of solids and liquids. 


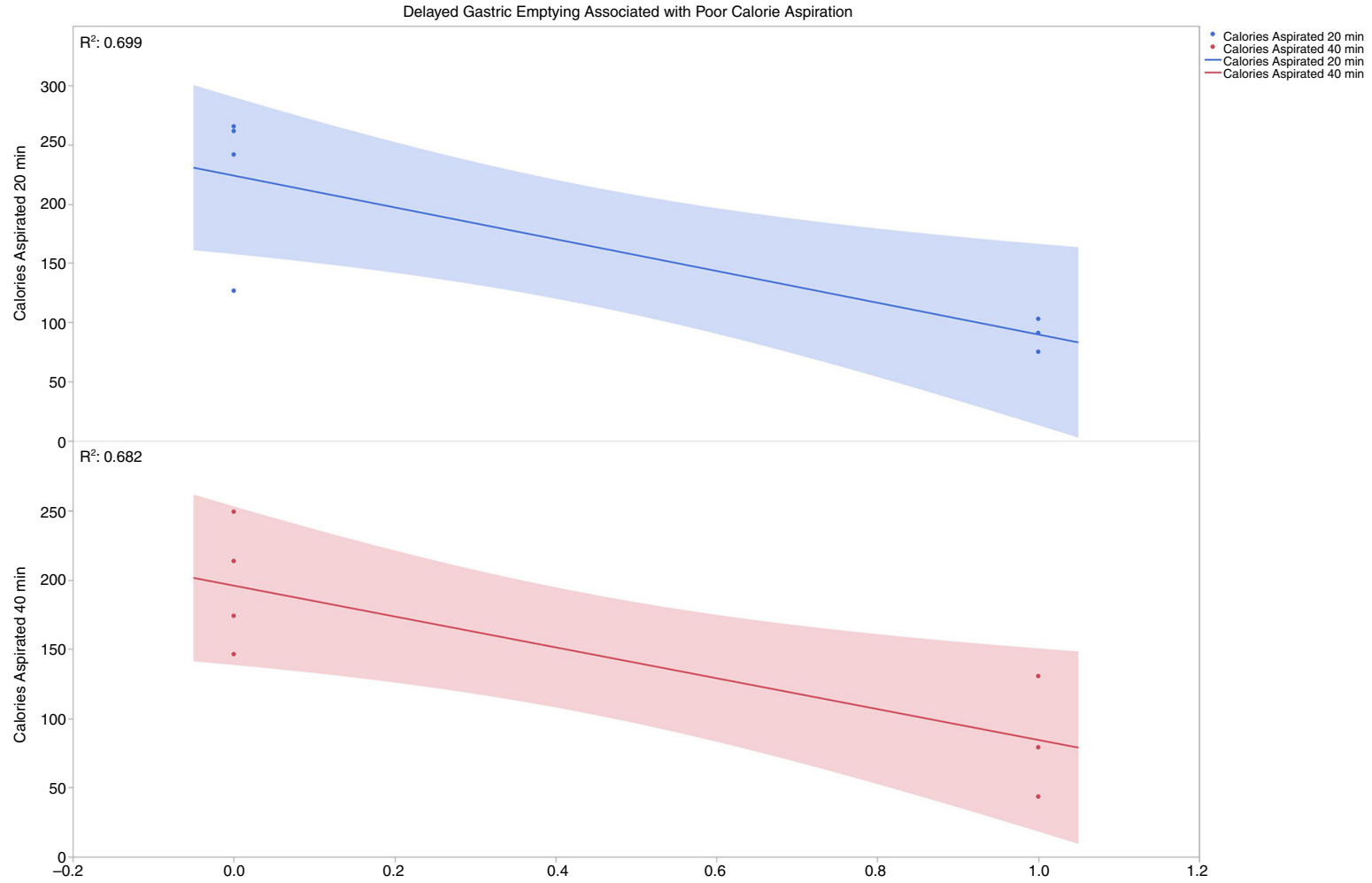

Figure 2 Delayed gastric emptying associated with poor aspiration at 20 (red) and 40 (blue) min.

\section{Aspiration efficacy}

Solid median aspiration efficacy did not significantly differ between the 20 and $40 \mathrm{~min}$ time points for the group as a whole: $32 \%$ vs $37 \% \quad(p=0.46)$. However, when stratified by baseline GE $\mathrm{T}_{1 / 2}(<94$ vs $\geq 94 \mathrm{~min})$, the median aspiration at both $20 \mathrm{~min}(63.5 \%$ vs $23 \%$; $\mathrm{p}=0.033)$ and $40 \mathrm{~min}(49 \%$ vs $20 \%$; $\mathrm{p}=0.034)$ was significantly different, with higher aspiration for the faster emptying group. When estimating calories aspirated at 20 min, the 'fast' group aspirated a median $200 \mathrm{kcal}$ vs $72.5 \mathrm{kcal}$ in the slow group ( $\mathrm{p}=0.05)$, and at $40 \mathrm{~min}$, the 'fast' group aspirated $154 \mathrm{kcal}$ vs $63 \mathrm{kcal}$ in the slow group $(\mathrm{p}=0.05)$.

\section{Association between baseline GE and aspiration efficacy}

On exploratory linear regression, baseline GE was significantly associated with the residual aspirated at both 20 and $40 \mathrm{~min}$, with those having a GE time $\left(\mathrm{T}_{1 / 2}\right)$ greater than $94 \mathrm{~min}$ associated with less calories aspirated (20 min: $\beta=-107$ calories; $p=0.019 ; R^{2}=0.7$ and 40 min: $\beta=-89$ calories; $p=0.02 ; \mathrm{R}^{2}=0.68$ ) (figure 2 ).

\section{Personalising AT}

When calculating the per cent change in calories aspirated between the 20 and $40 \mathrm{~min}$ aspirations using 20 min as a baseline, four out of the seven patients would have benefited from a baseline GE assessment, with almost a $50 \%$ change in calories/residual aspirated detected. Two patients would have increased their aspiration if they aspirated at $40 \mathrm{~min}$, and two patients aspirate more at $20 \mathrm{~min}$. In three patients, no significant differences were found between the two time points (figure 3).

\section{DISCUSSION}

In this prospective ancillary study involving patients using AT for treatment of obesity we identified a few key findings. First, there was no overall significant difference in efficacy at 20 vs 40 min found between subjects. However, when we assessed differences by baseline GE, significant differences were found. Interestingly, subjects with faster GE had better aspiration overall, whether performed at 20 or $40 \mathrm{~min}$. This finding is paradoxical, since faster emptying would suggest aspirating at an earlier time point would allow for a larger bolus of food to be disposed of. Potential mechanisms may be behind the difference in the $\mathrm{T}_{\text {lac }}$ time between groups, or the position the modified PEG tube lies in the stomach. The delayed GE subjects may need to aspirate at an even later time point improved efficacy, or should undergo a different treatment for obesity altogether. Overall, differences in GE and subsequent aspiration efficacy may be responsible for those who are failing to lose weight, such as the differences seen in the early responders during the PATHWAY study.

The era of personalised obesity management is quickly approaching with office-based tools to predict and prognostic patient's response to lifestyle interventions, medications and endoscopic bariatrics. ${ }^{56-11}$ AT is an option for patients with class II-III obesity with reservations about bariatric surgery. Gastric scintigraphy may 


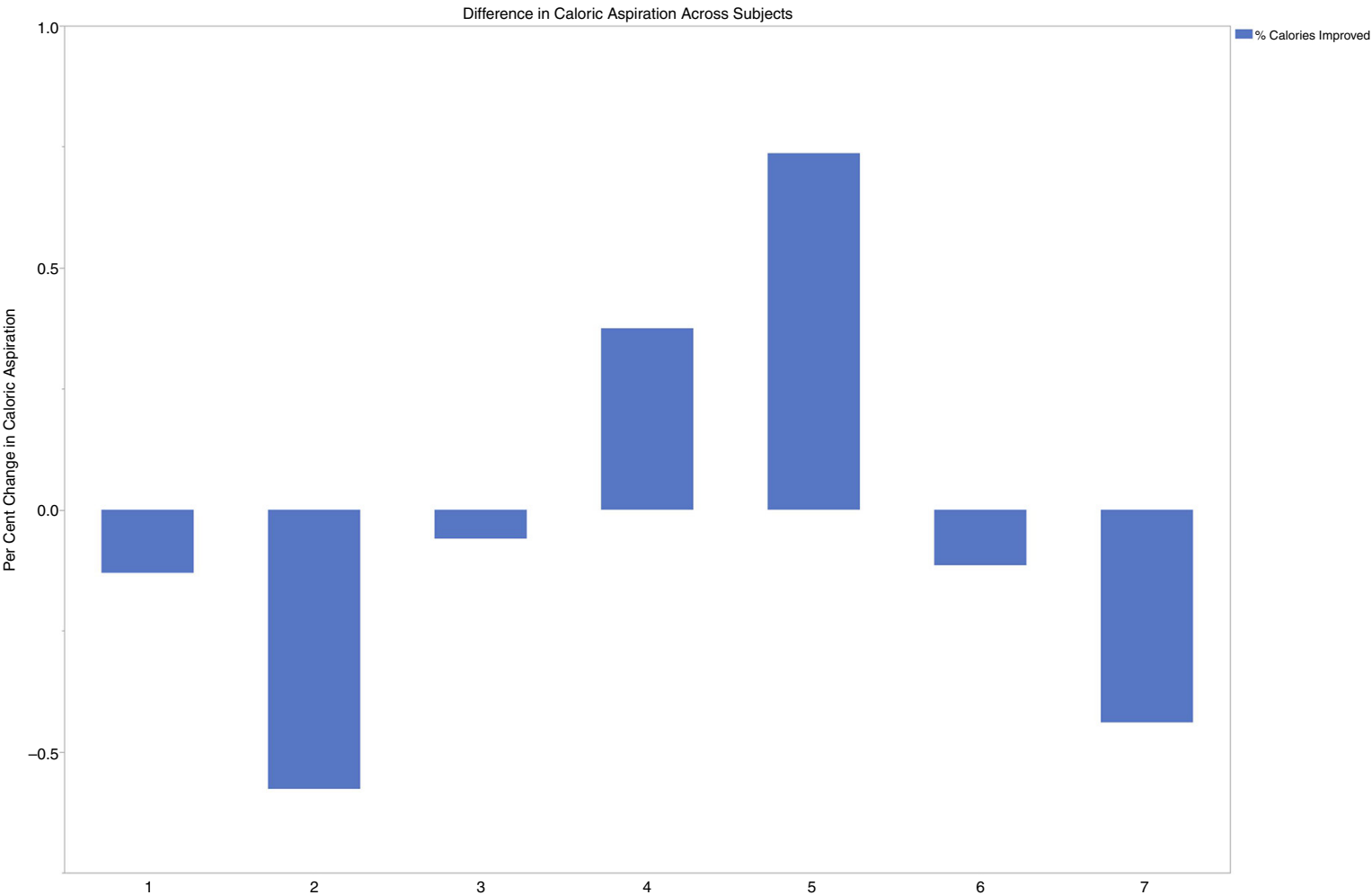

Figure 3 Waterfall plot showing over $50 \%$ of subjects had significant changes in caloric aspiration across time points.

be a useful addition to maximise treatment response, as we were able to detect clinically meaningful changes in calorie aspiration in over $50 \%$ of our study subjects.

While the limitations of our study include its small sample size, selection bias and single-centre design, our strengths include its prospective design, and gold standard scintigraphic methods for GE assessment. Overall, future prospective studies evaluating the use of GE and subsequent AT response are needed to validate our findings.

Contributors EJV: drafting of the manuscript and analysis/interpretation of data. ACS and FB: critical revision of the manuscript. BKAD: obtaining funds, critical revision of manuscript and interpretation of data.

Funding ASPIRE Bariatrics, King of Prussia, PA 19406 USA and UL1 TR000135.

Competing interests BKAD reports grants from Aspire Bariatrics during the conduct of the study; grants from GI Dynamics, grants from Apollo Endosurgery, personal fees from USGI, grants from Medtronic, grants from Spatz, grants from Cairns, personal fees from Boston Scientific, personal fees from Olympus, personal fees from Johnson and Johnson, personal fees from BKFW outside the submitted work.

Patient consent for publication Not required.

Provenance and peer review Not commissioned; externally peer reviewed.

Data sharing statement No additional data are available.

Open access This is an open access article distributed in accordance with the Creative Commons Attribution Non Commercial (CC BY-NC 4.0) license, which permits others to distribute, remix, adapt, build upon this work non-commercially, and license their derivative works on different terms, provided the original work is properly cited, appropriate credit is given, any changes made indicated, and the use is non-commercial. See: http://creativecommons.org/licenses/by-nc/4.0/.

\section{REFERENCES}

1. Thompson CC, Abu Dayyeh BK, Kushner R, et al. Percutaneous gastrostomy device for the treatment of class II and class III obesity: results of a randomized controlled trial. Am J Gastroenterol 2017; 112:447-57.

2. Nyström M, Machytka E, Norén E, et al. Aspiration therapy as a tool to treat obesity: 1 - to 4-year results in a 201-patient multi-center post-market European registry study. Obes Surg 2018;28:1860-8.

3. Abu Dayyeh BK, Acosta A, Camilleri M, et al. Endoscopic sleeve gastroplasty alters gastric physiology and induces loss of body weight in obese individuals. Clin Gastroenterol Hepatol 2017:15:37-43.

4. Chedid V, Vijayvargiya P, Carlson P, et al. Allelic variant in the glucagon-like peptide 1 receptor gene associated with greater effect of liraglutide and exenatide on gastric emptying: a pilot pharmacogenetics study. Neurogastroenterol Motil 2018;30:e13313.

5. Halawi $\mathrm{H}$, Khemani $\mathrm{D}$, Eckert $\mathrm{D}$, et al. Effects of liraglutide on weight, satiation, and gastric functions in obesity: a randomised, placebocontrolled pilot trial. Lancet Gastroenterol Hepatol 2017;2:890-9.

6. Camilleri M, Acosta A. Gastrointestinal traits: Individualizing therapy for obesity with drugs and devices. Gastrointest Endosc 2015 (Epub 2015/08/15).

7. Acosta A, Camilleri M, Shin A, et al. Quantitative gastrointestinal and psychological traits associated with obesity and response to weightloss therapy. Gastroenterology 2015;148:e4:537-46.

8. Sullivan S, Stein R, Jonnalagadda S, et al. Aspiration therapy leads to weight loss in obese subjects: a pilot study. Gastroenterology 2013;145:1245-52.

9. Abu Dayyeh BK, Lopez-Nava G, Bautista-Castaño I, et al. Personalization of bariatric and metabolic endoscopy therapies based on physiology: a prospective feasibility trial with the single fluid-filled intragastric balloon. Gastrointest Endosc 2018;87(Suppl 1).

10. Abu Dayyeh BK, Woodman G, Acosta A, et al. Baseline gastric emptying and its change in response to diverse endoscopic bariatric therapies predict weight change after intervention. Gastroenterology $2016 ; 1$.

11. Camilleri M, Acosta A. Gastrointestinal traits: individualizing therapy for obesity with drugs and devices. Gastrointest Endosc 2016;83:48-56. 